\title{
A New Artificial Neural Network Based Failure Determination System For Electric Motors
}

\section{Sabri Bicakci}

Balikesir University: Balikesir Universitesi

\section{Mustafa Coramik}

Balikesir University: Balikesir Universitesi

\section{Huseyin Gunes}

Balikesir University: Balikesir Universitesi

\section{Hakan Citak}

Balikesir University: Balikesir Universitesi

Yavuz Ege ( $\square$ yavuzege@gmail.com )

Balikesir Universitesi https://orcid.org/0000-0002-8610-2539

\section{Research Article}

Keywords: Single phase capacitor start motor, Vibration sensor, Artificial neural network, LabVIEW

Posted Date: February 4th, 2021

DOI: https://doi.org/10.21203/rs.3.rs-172846/v1

License: (c) (1) This work is licensed under a Creative Commons Attribution 4.0 International License. Read Full License

Version of Record: A version of this preprint was published at Arabian Journal for Science and Engineering on April 7th, 2021. See the published version at https://doi.org/10.1007/s13369-021-055948. 


\section{Abstract}

A new measurement system was developed for determination of failures and defining the level of failure that may occur in bearings and rotor bearings or in foot of motor in single phase capacitor start motor. In system, the vibratory operation of the motor is provided by connecting different screws on the motor's rotor mounted flywheel or by gradually removing the nut bolts of motor foot. The VB3 vibration sensor outputs were recorded to the computer. The changing characteristics of sensor output for each experiment had more than one frequency component; therefore, FFT was performed for determining such components. It was observed that the frequency and amplitude values of first 5 harmonics could be used for determining the presence, type and level of failure but there was a nonlinear relation between each other. 2 different ANN customized separately were developed for determining the type and rate of the failure of motor. $80 \%, 10 \%$ and $10 \%$ of available data were reserved for training, testing and verification respectively and the ANN was trained. Accuracy degree for the ANN in the estimations following the training stage was calculated as $\mathrm{R}=0.97-0.98$. Furthermore, the results of ANN was compared with the results obtained using Sequential Minimal Optimization (SMO), Naive Bayes (NB) and J48 algorithms; and it was determined that the accuracy degree of ANN was higher.

\section{Full Text}

This preprint is available for download as a PDF.

\section{Declarations}

The authors declare no competing interests

\section{Figures}
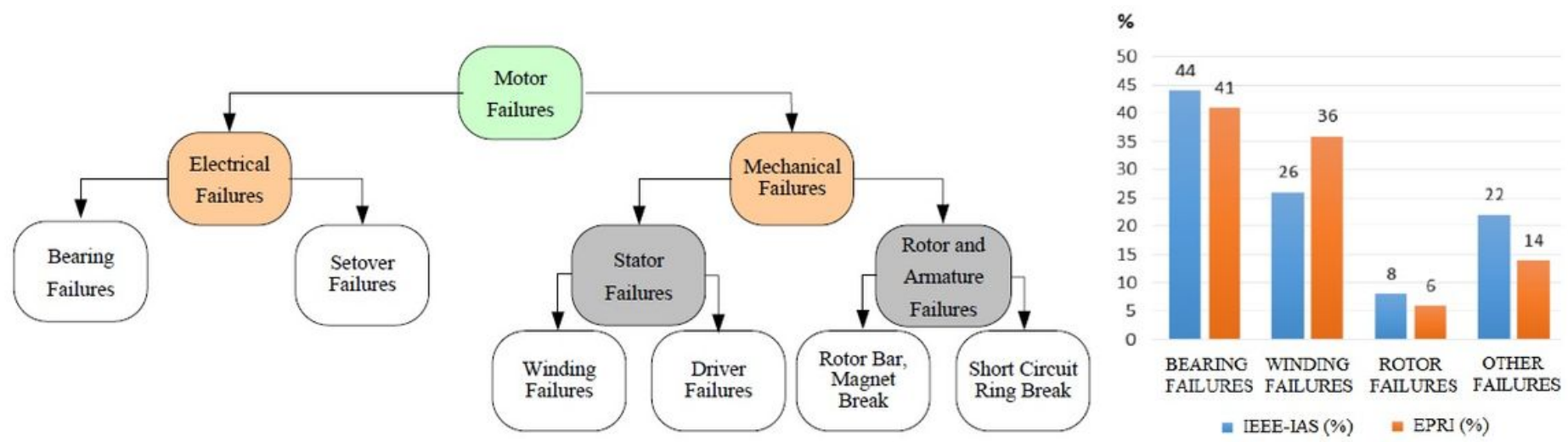

Figure 1

Failure types and their proportional distribution in asynchronous motors. 


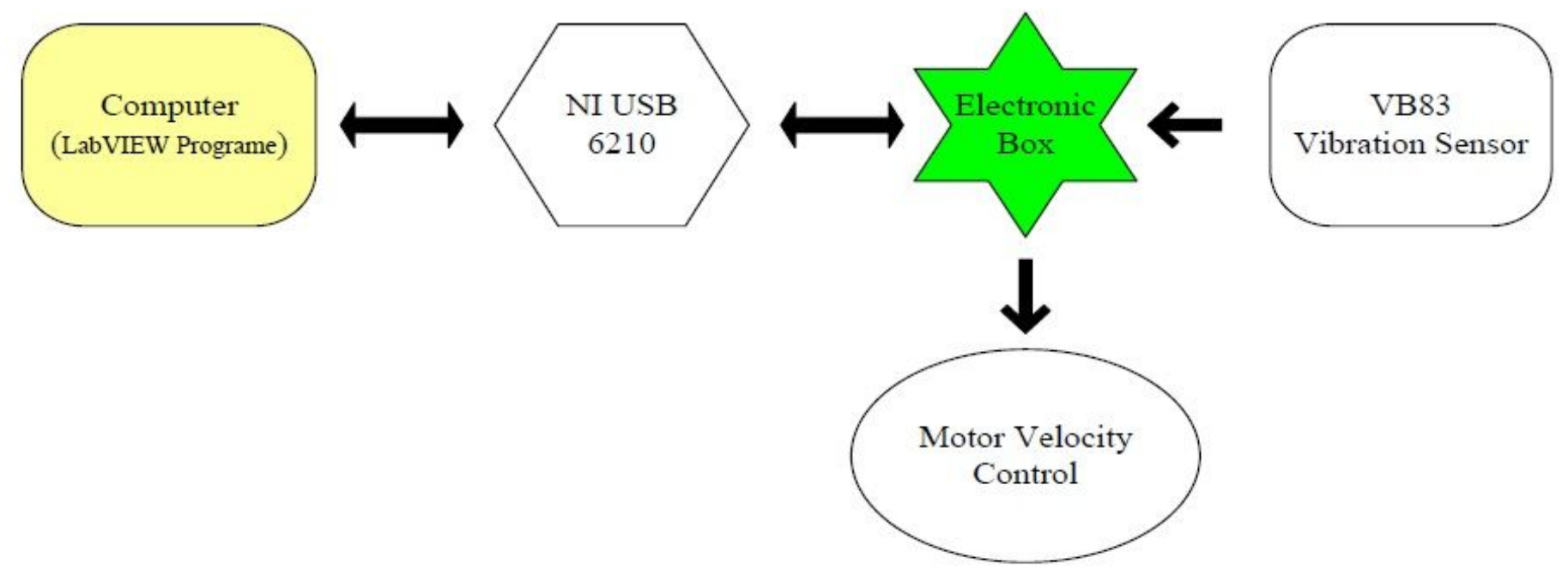

Figure 2

Block system of the failure determination and identification system developed.
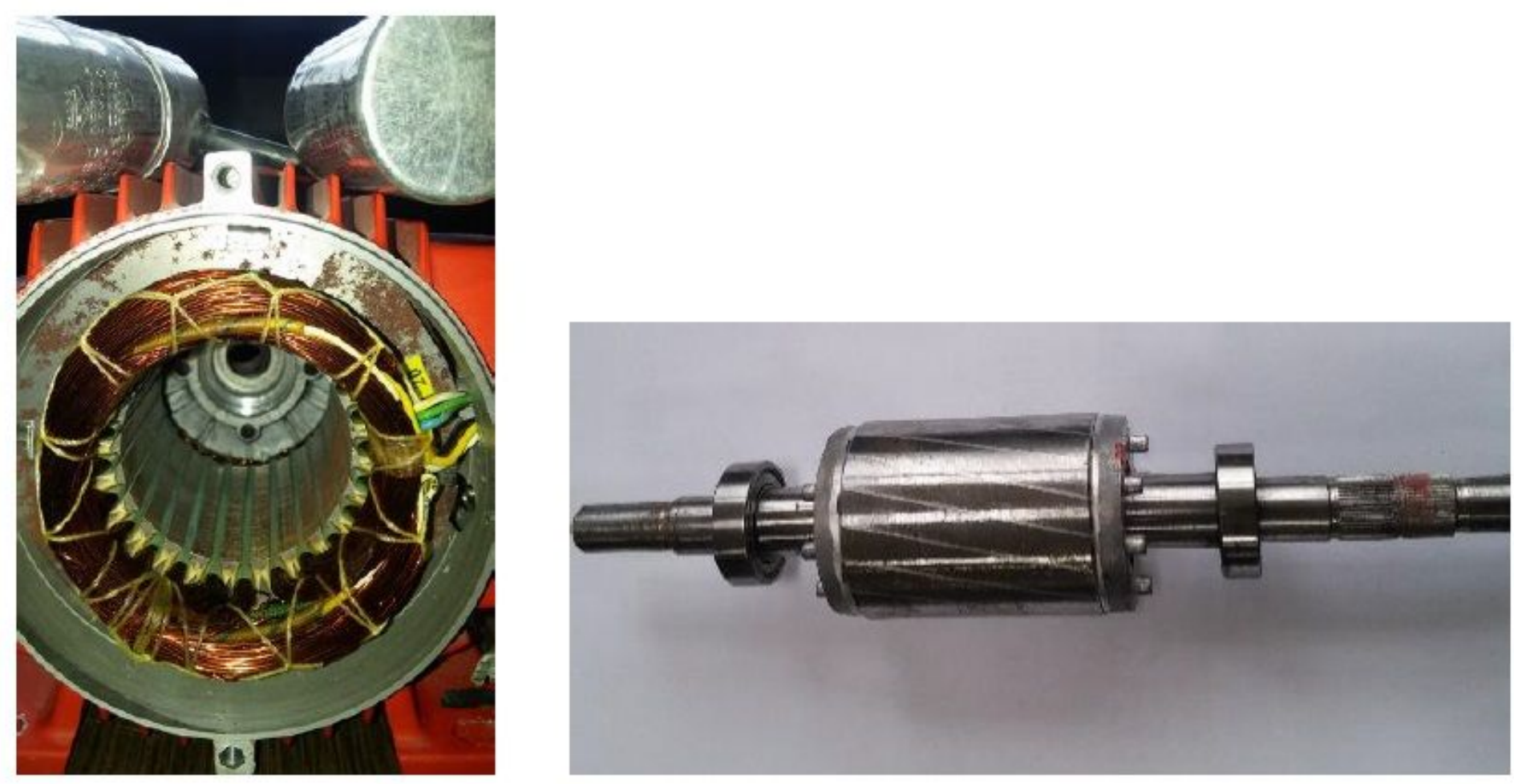

Figure 3

Photos of stator and rotor of the motor tested. 


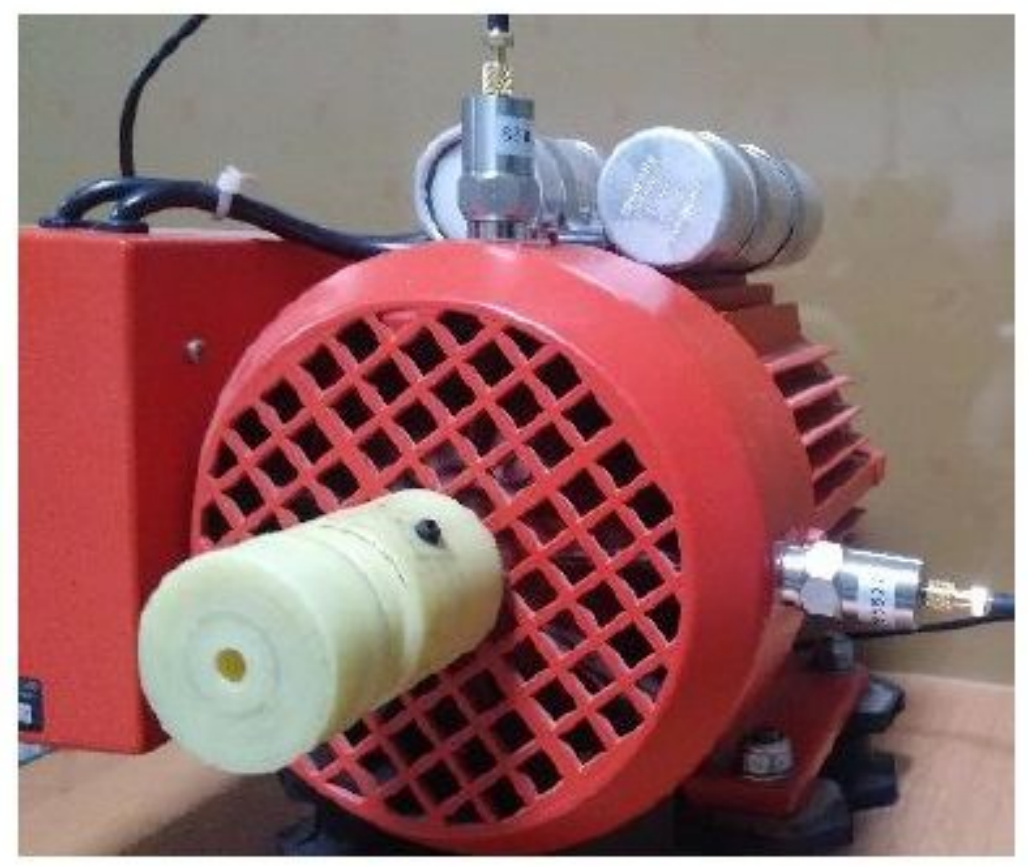

\section{Figure 4}

Locations of VB83 vibration sensors on the motor.
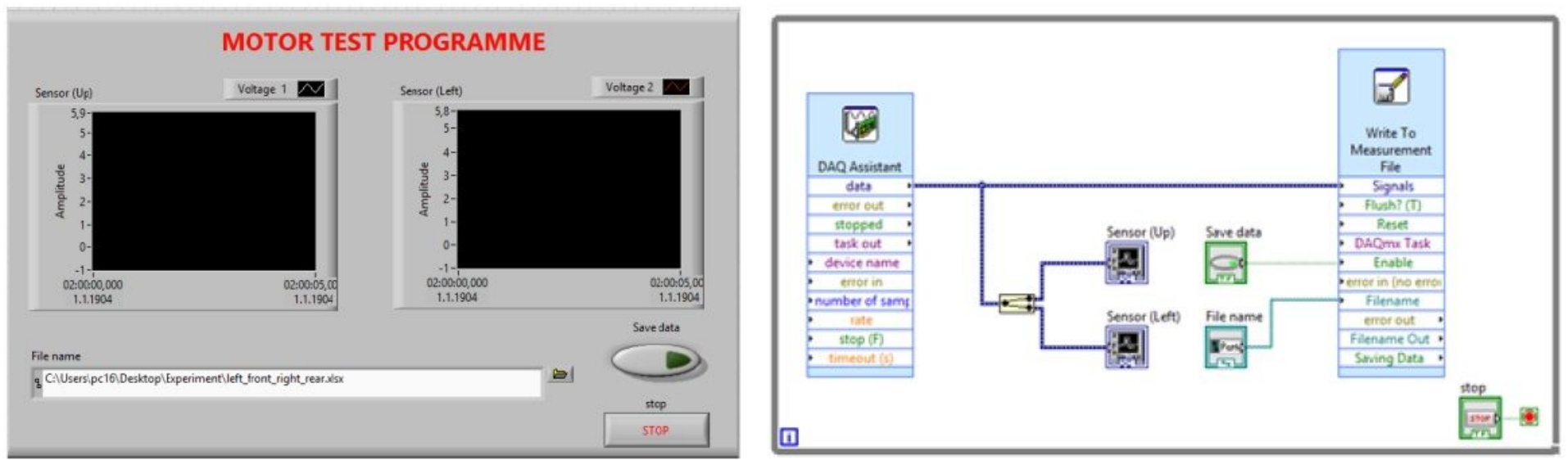

Figure 5

Front panel and block diagram of LabVIEW program developed.

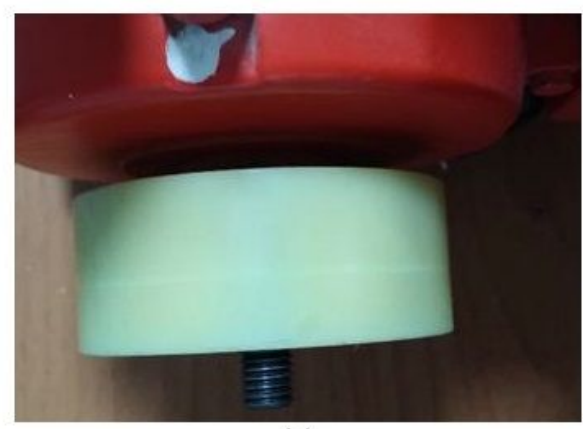

(a)

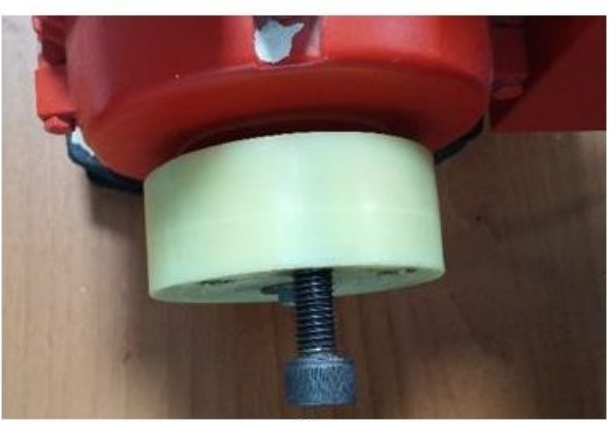

(b)

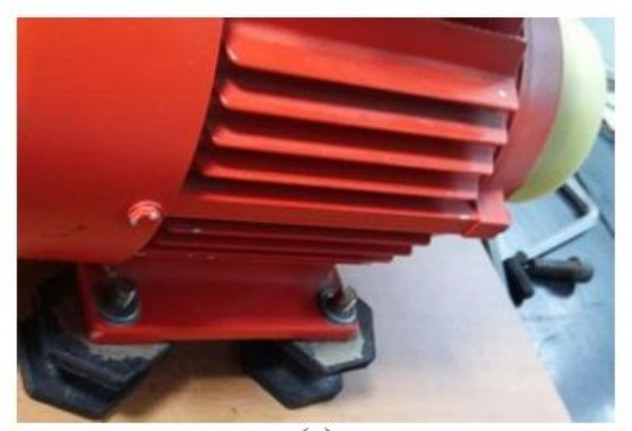

(c) 
Figure 6

a) Representation of bearing damage, b) Representation of rotor bearing damages, c) Representation of foot damages of motor.

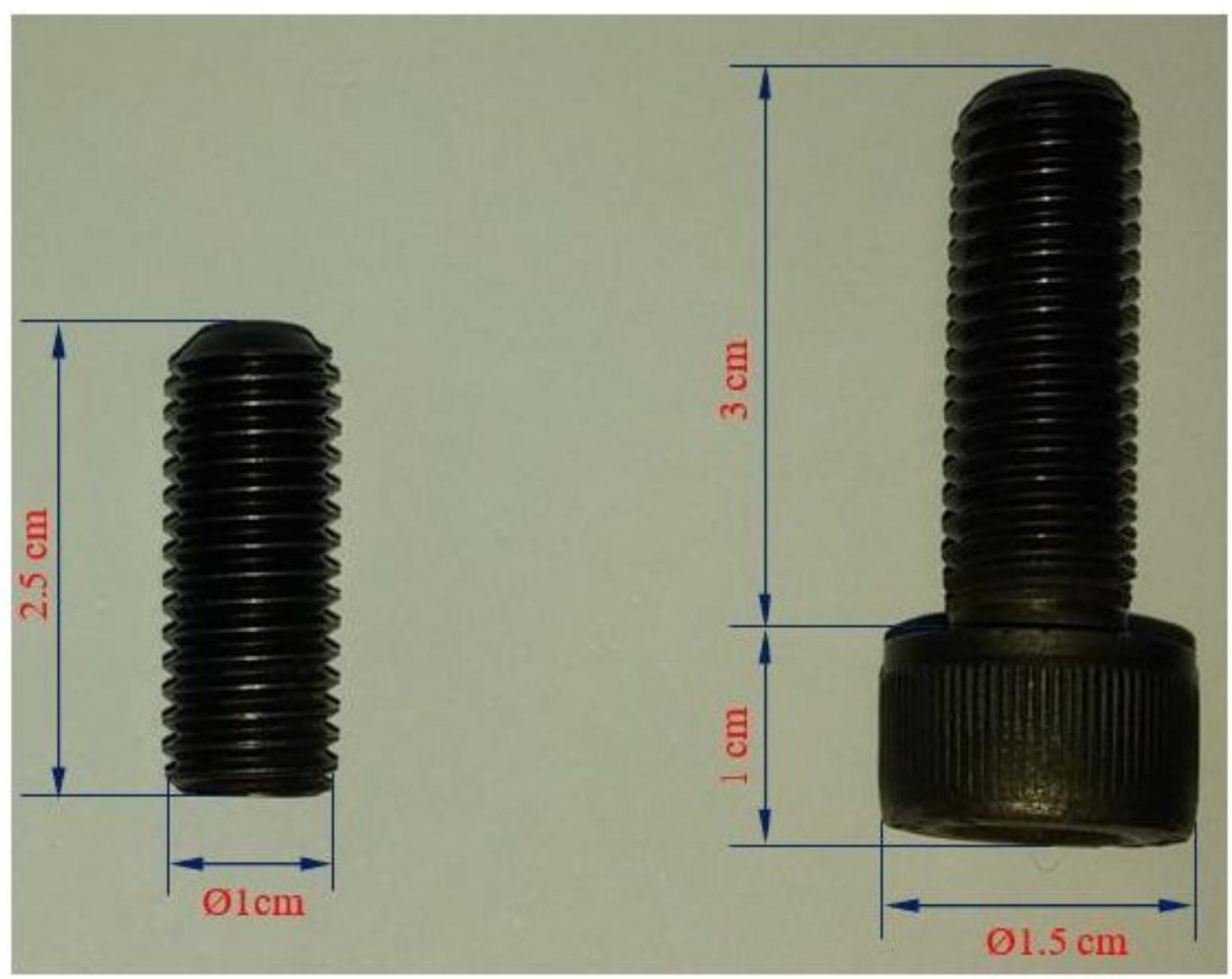

Figure 7

Photos of 1st Screw and 2nd Screw 


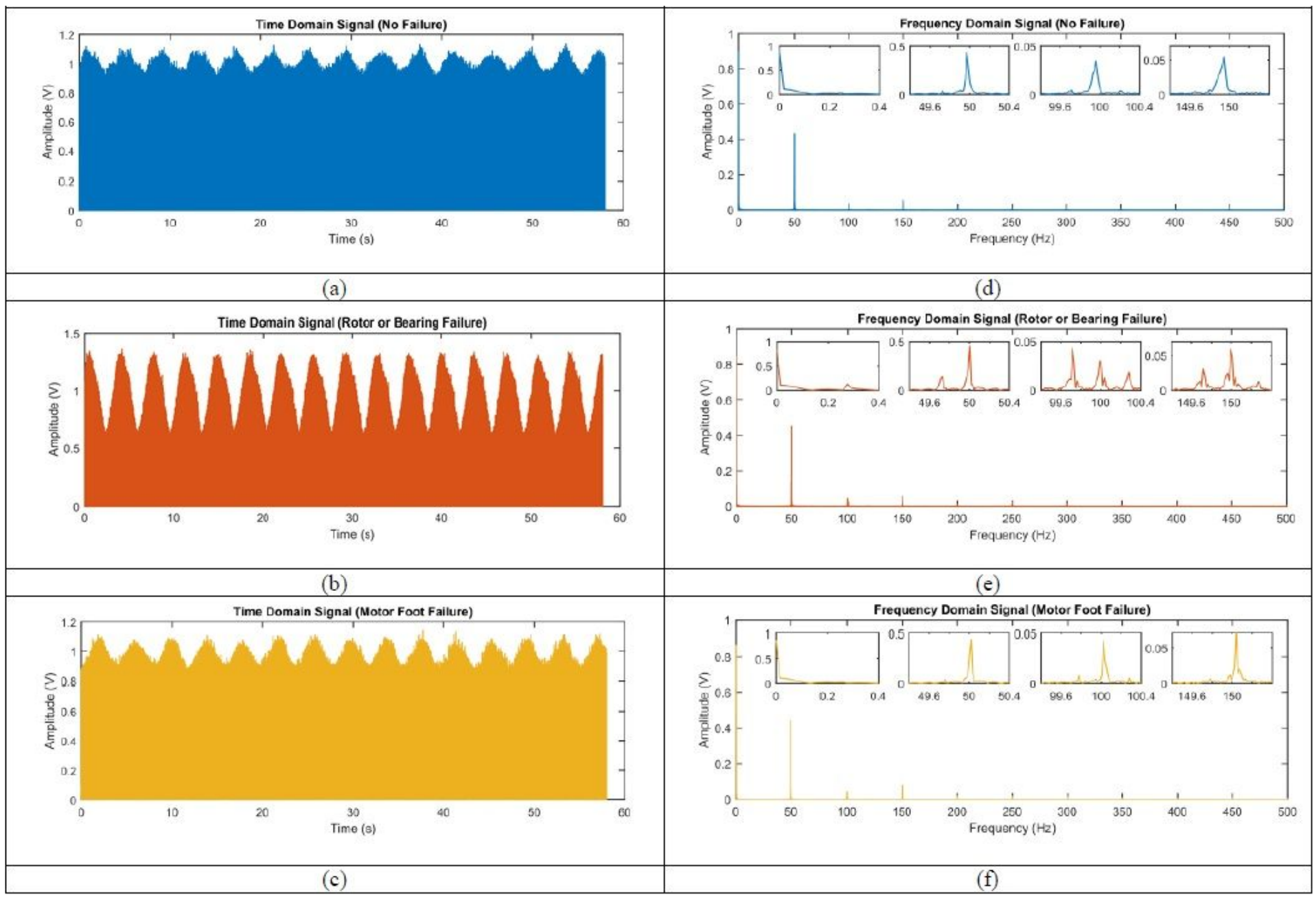

\section{Figure 8}

Time domain signal of a) no failure b) rotor or bearing failure c) motor foot failure. Frequency domain signal of d) no failure e) rotor or bearing failure f) motor foot failure. 


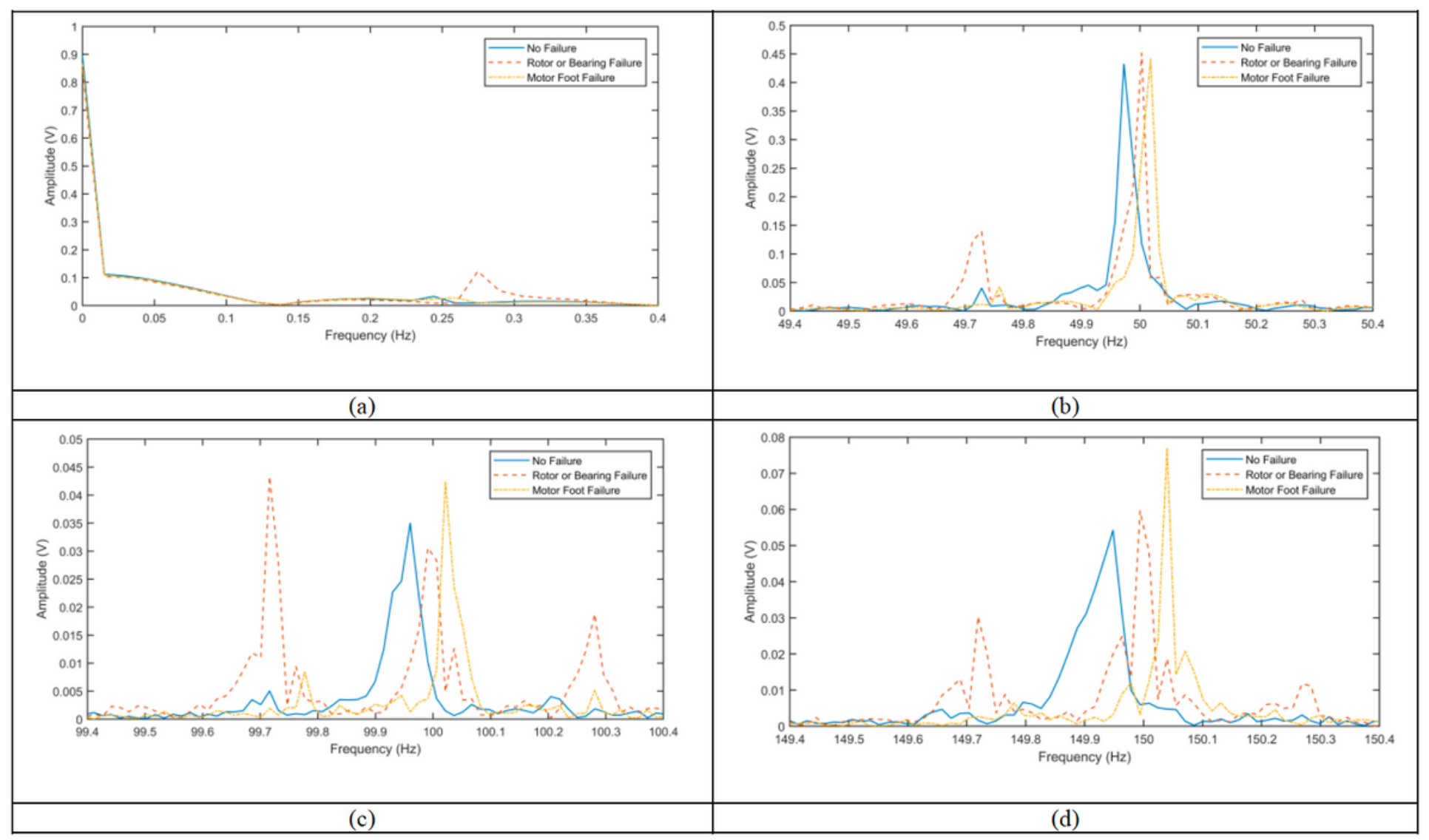

Figure 9

Close examination of FFT graphs based on the failure type of each harmonic fields between a) 0-0.4 Hz b) $49.4-50.4$ c) $99.4-100.4$ d) $149.4-150.4$.

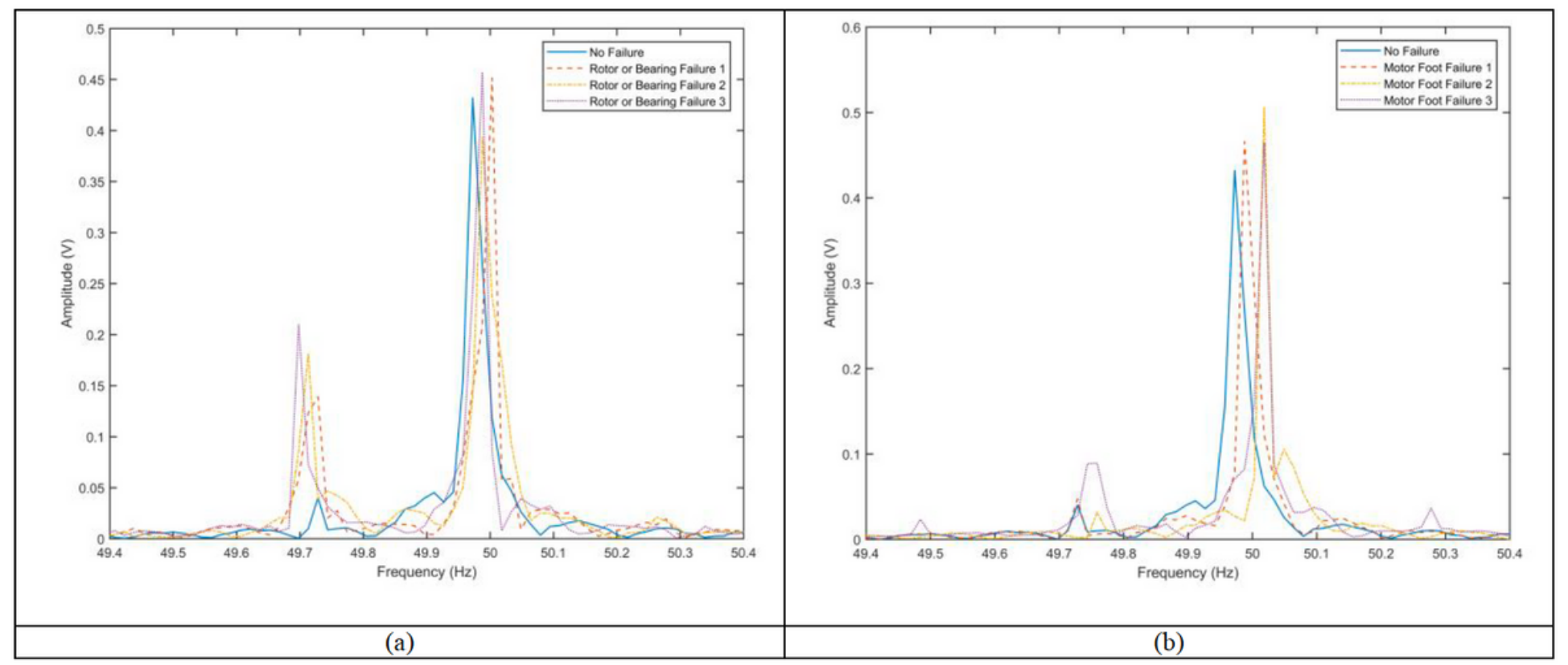

Figure 10 
Close examination of FFT graphs based on the failure level of one harmonic field ( $50 \mathrm{~Hz})$ for a) rotor or bearing failure b) motor foot failure.

\section{FFT and Determination of Highest 5 Amplitude Values in 4 Fields}

\section{$1^{\text {st }}$ ANN - Determination of Motor Failure and Type}
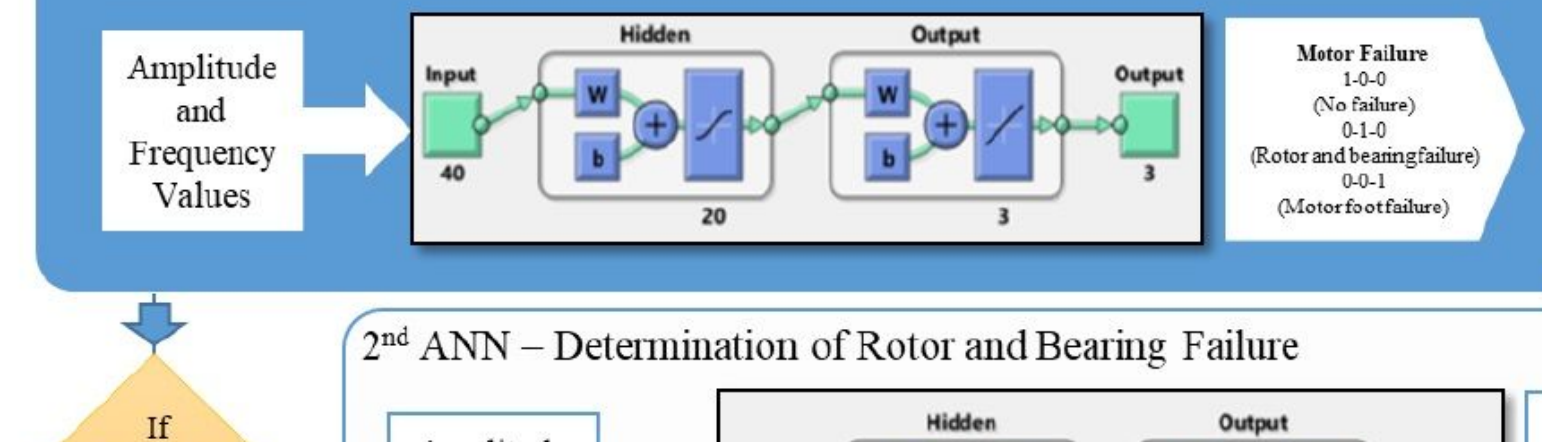

Rotor and

Bearing

Failure

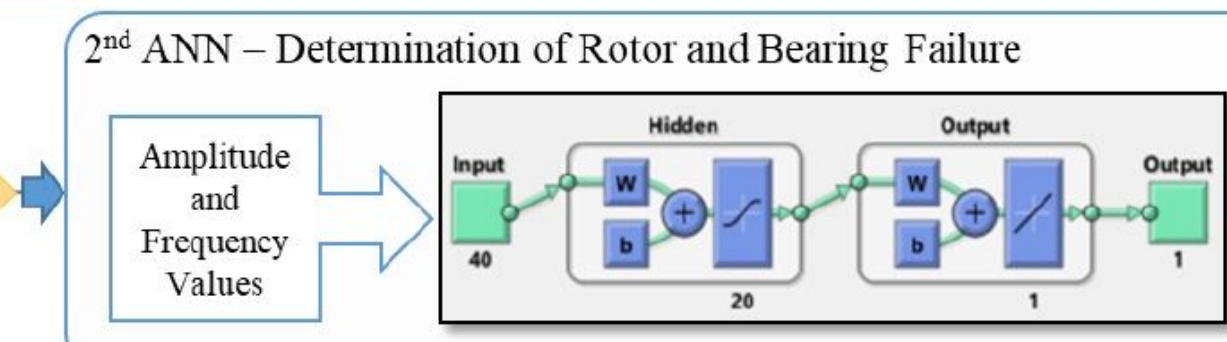

Failure Level \%

\section{Figure 11}

Flow chart of the MATLAB program developed and the ANNs.

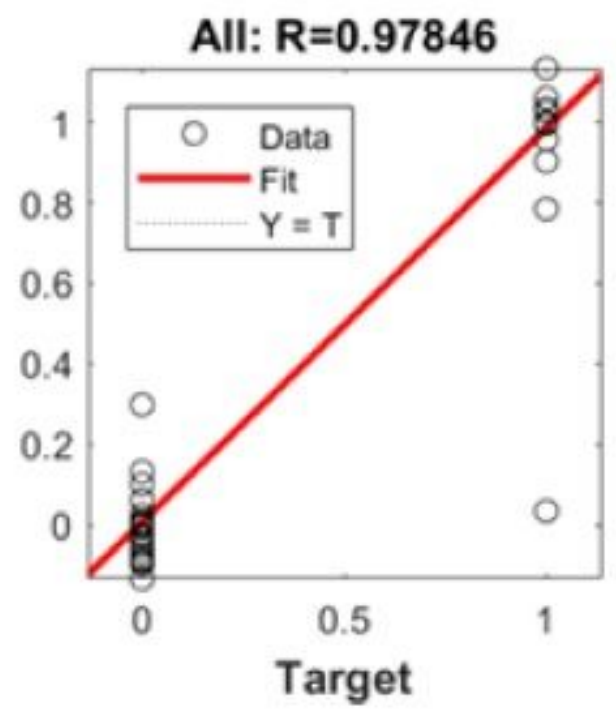

Figure 12

Result of 1 st ANN. 


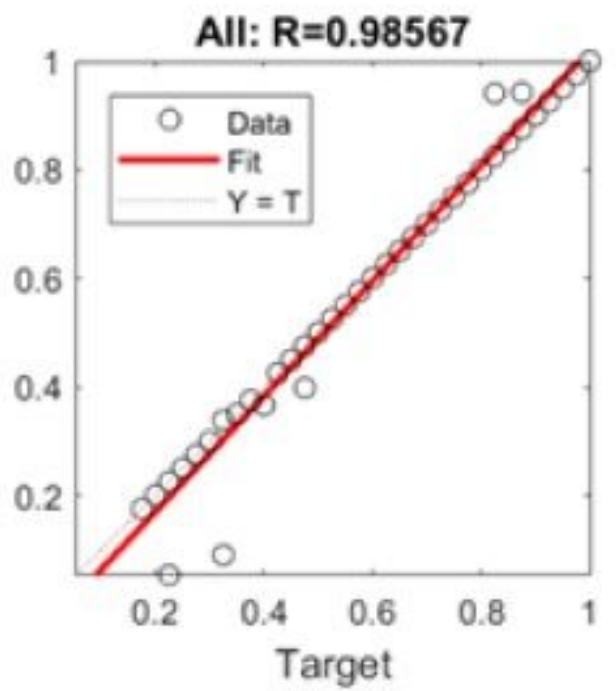

Figure 13

Result of 2nd ANN. 


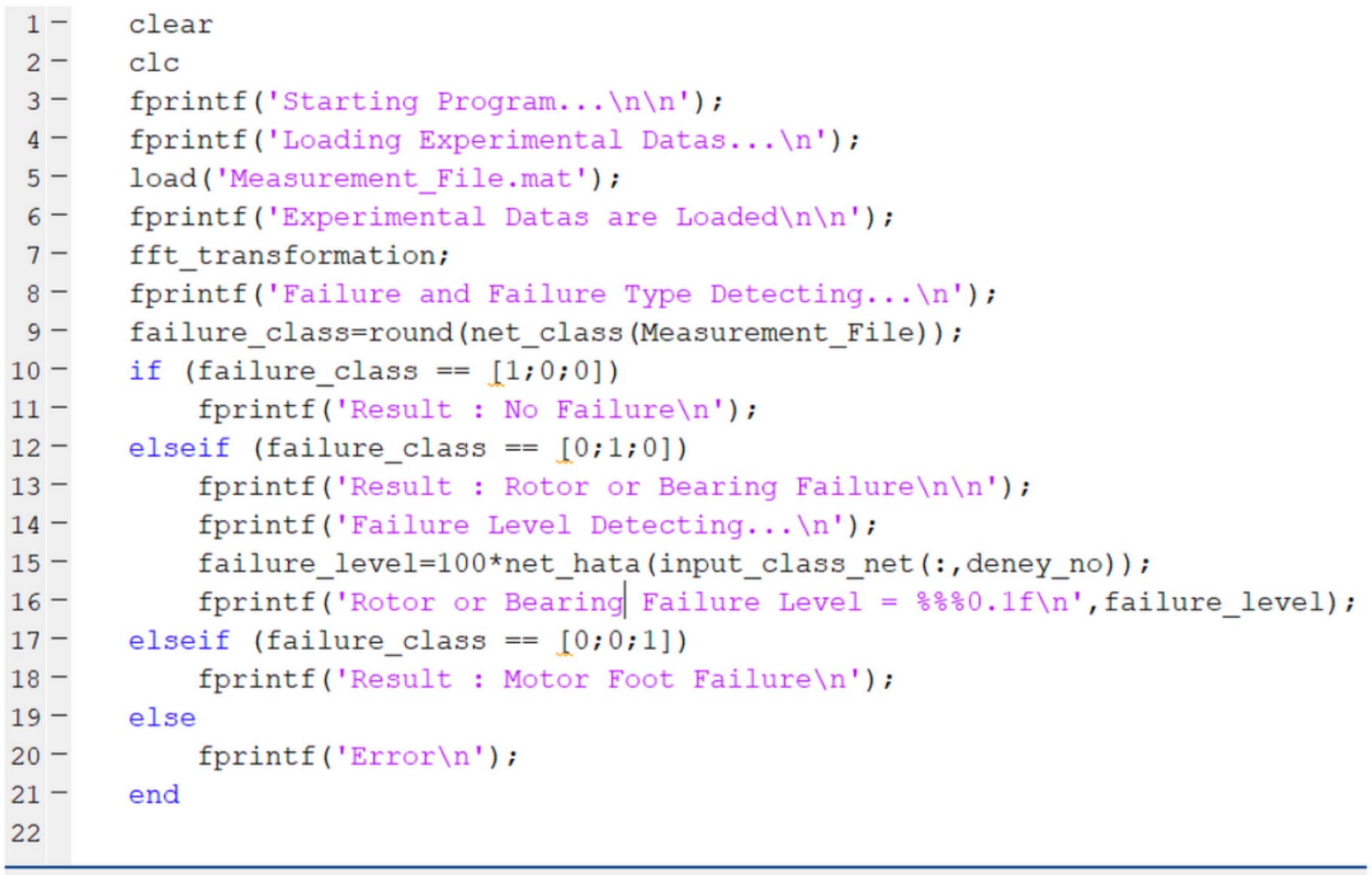

\section{Command Window}

New to MATLAB? See resources for Getting Started.

Starting Program...

Loading Experimental Datas...

Experimental Datas are Loaded

Calculating FFT for Measurement Datas...

Failure and Failure Type Detecting...

Result : Rotor or Bearing Failure

Failure Level Detecting...

Rotor or Bearing Failure Level $=\div 50.2$

$f x>>$

\section{Figure 14}

Program and output for rotor or bearing failure and level 


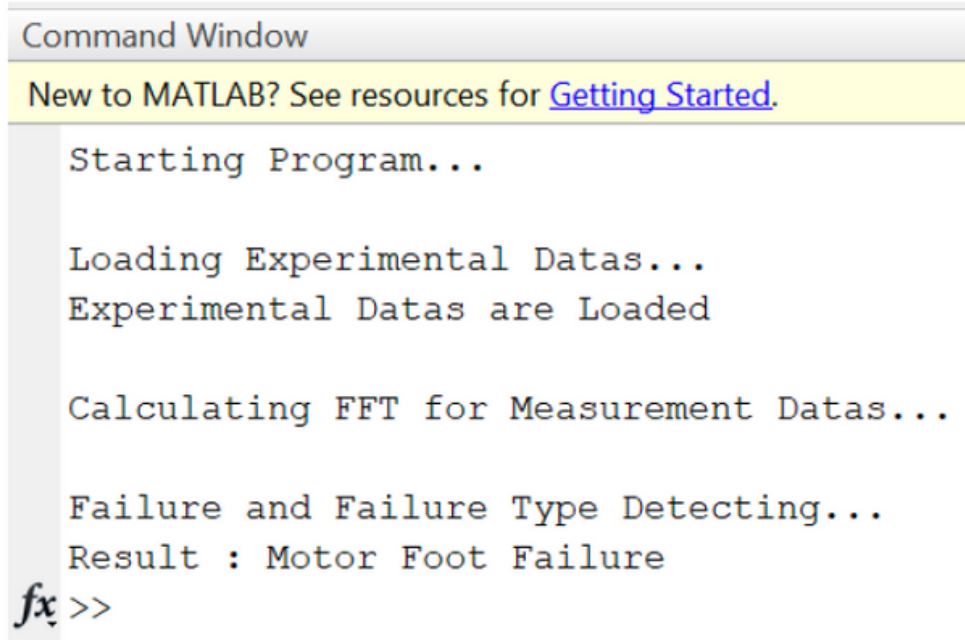

\section{Figure 15}

Output of motor foot failure
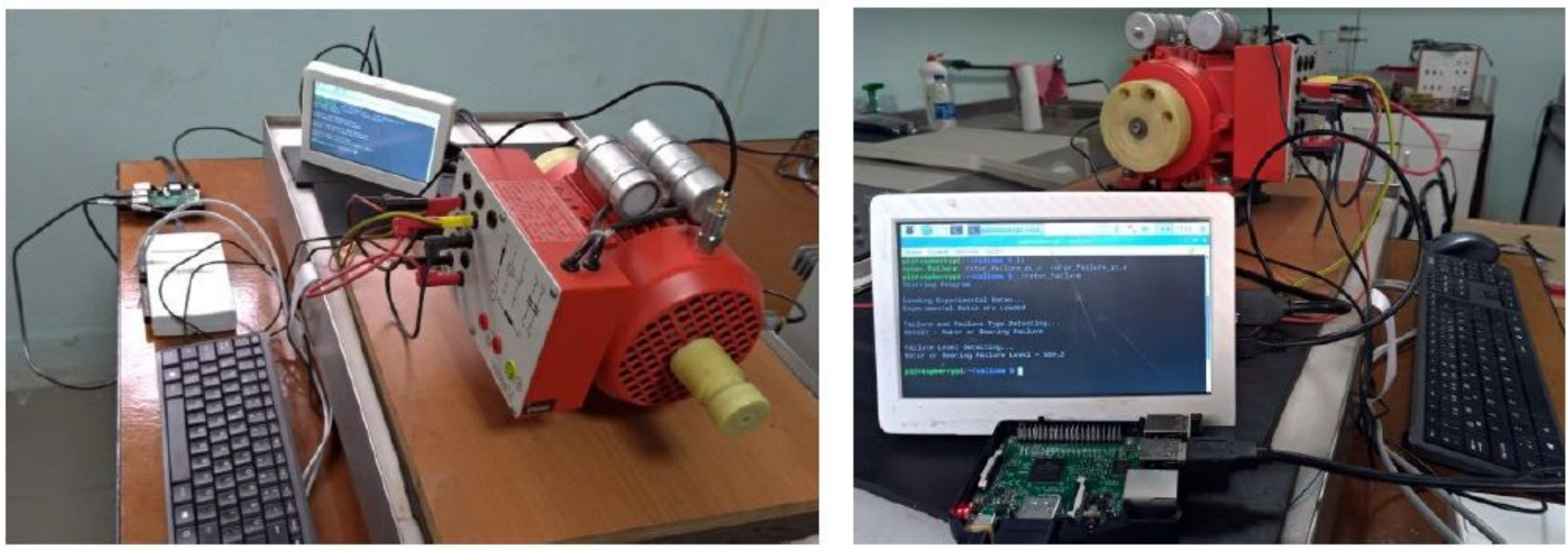

Figure 16

Verification application with Raspberry Pi 


\section{Thermal Camera}

15

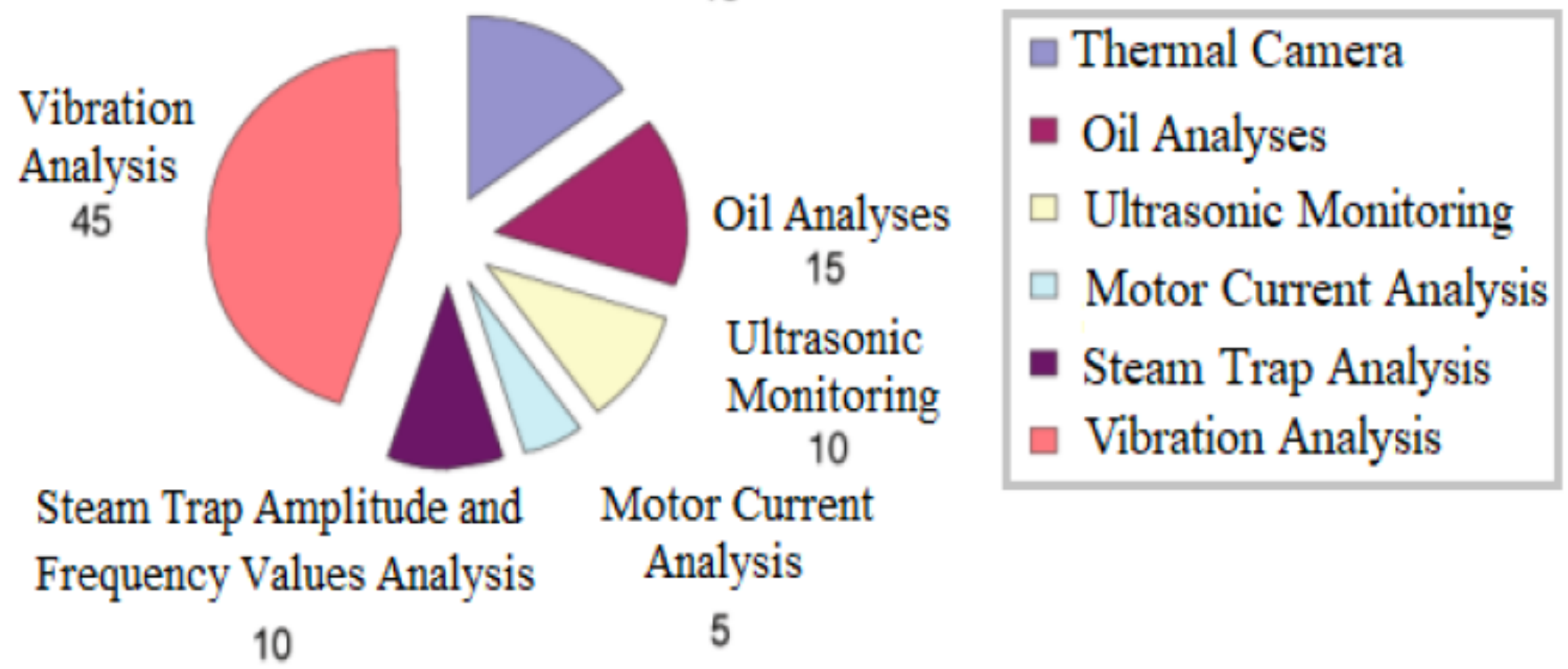

Figure 17

Rate of usage for predictive maintenance approach in the determination of failures. 